\title{
Morphological Characterization of Porous Anodic Alumina Membranes Prepared in Sulphuric, Oxalic, Chromic and Phosphoric Acids
}

\author{
P. Ramana Reddy ${ }^{1,2, *,\left(\mathbb{D}, \text { Ajith K.M. }{ }^{2}, \text { N.K. Udayashankar }\right.}{ }^{2}$
}

Porous Anodic Alumina membranes (PAAM) have a significant role in nanoscale devices due to their easily tunable structural aspects and variety of applications in nanotechnology. The variable process parameters in the synthesis of PAAM were anodization potential, temperature, duration and nature of electrolyte concentration. Pores of different sizes and geometry were obtained by varying these anodization parameters. In the present work, PAAM were prepared in $0.3 \mathrm{M}$ of sulphuric, oxalic, chromic and phosphoric acids as electrolyte and with anodization potentials $(20,40,50$ and $90 \mathrm{~V})$ at a temperature of $8{ }^{\circ} \mathrm{C}$. Field-emission Scanning Electron Microscopy investigations confirm the pore formation in PAAM layers. Pore ordering was calculated using the Fast Fourier transform (FFT) of top view SEM micrographs. Pore arrangement analysis of PAAM was studied using Image-J and WSxM software. Morphological features of PAAM such as pore diameter, interpore distance, porosity and pore density were calculated in all electrolytes. Results show that, PAAM formed in oxalic acid having high regularity ratio and circularity compared with other cases.

\section{Introduction}

Anodization of aluminium is a simple, low cost and electrochemical process that results formation of porous anodic alumina membranes (PAAM) of different morphology by varying process parameters such as anodization potential $[1]$, duration $[2,3]$, temperature [4-6] and nature of electrolyte concentration [7-9]. Many research groups have intensively working on optimization of synthesis part of PAAM, having applications in electronics and photonics [10], energy storage [11], sensors [12], drug delivery [13] and to obtain nanotubular materials [14]. To reduce high current densities results from oxide dissolution, most of the researchers have studied anodization of aluminium at low temperatures $\left(0-8^{\circ} \mathrm{C}\right)$ [15-16]. This gives slow oxidation growth rate [17], which requires long anodization duration for the preparation of PAAM. The structural aspects of PAAM such as oxide growth rate and barrier layer thickness strongly depends on anodization potential was

\footnotetext{
'Department of Physics, Vignan's Foundation for Science, Technology and Research, Vadlamudi, Guntur 522213, Andhra Pradesh, India

${ }^{2}$ Department of Physics, National Institute of Technology Karnataka, Surathkal, Mangalore 575025, India

${ }^{*}$ Corresponding author:

E-mail: ramana.nitk@gmail.com
}

DOI: 10.5185/aml.2021.15704 some of the researchers already studied [18]. Both pore diameter and interpore distance increases linearly with increasing anodization potential [19], electrolyte concentration [20] were already reported.

Mask fabrications [21], lithography techniques [22,23] and plasma treatments [24] are generally used methods to prepare PAAM with better pore arrangement and hexagonal array structure. Some of the drawbacks using these methods are: time-consuming, high cost and scaling limitations. Two-step anodization process is the simplest way to prepare highly ordered PAAM structures [25-26]. After formation of the first step layer, subsequently removed and followed by second step with same anodizing conditions. Chosen of anodizing conditions are critical parameters for achieving PAAM with highly uniform ordered porous structure [27]. Aluminium grain sizes, impurity concentrations and the local crystal orientation of Al play a major role in fabrication of PAAM [28]. Al substrate is having significant influence on the formation of better pore arrangement and highly ordered regularity of the pores [29]. In particular, optimization of process parameters and electrolyte concentration in oxalic acid was already studied $[\mathbf{3 0 , 2 0}]$. The main aim of the present work is to fabricate PAAM in different electrolytes and to study the circularity and degree of pore order in sulphuric, oxalic chromic and phosphoric acids. Herein, we demonstrated a detailed structural characterization of PAAM fabricated in $0.3 \mathrm{M}$ of sulphuric, oxalic, chromic and phosphoric acid as electrolytes. Mainly the structural aspects like pore 
diameter, interpore distance, porosity, pore density, circularity and regularity ratio of pores were analysed in all electrolytes. The present work highlights a complete morphological characterization of PAAM in sulphuric, oxalic, chromic and phosphoric acids.

\section{Experimental}

Initially, high purity $(99.998 \%, 0.3 \mathrm{~mm}$ thickness, Alfa Easer) annealed Al foil was cut into samples $(2.5 \times 1 \mathrm{~cm})$ with working area of $1 \mathrm{~cm}^{2}$. To remove the prevalent stress and strain and re-crystallize the surface along any particular direction, the $\mathrm{Al}$ foils were annealed at $500{ }^{\circ} \mathrm{C}$ for $5 \mathrm{~h} \mathrm{[2]}$. Before anodization, foils were decreased in $\mathrm{C}_{2} \mathrm{H}_{5} \mathrm{OH}$, followed by distilled water and electrochemically smoothed in a mixture of per chloric acid and ethanol (1:4 Volume ratio) at voltage of $15 \mathrm{~V}$, at $10{ }^{\circ} \mathrm{C}$ for $1 \mathrm{~min}[31,32]$. Then the samples were anodized in $0.3 \mathrm{M}$ of sulphuric, oxalic, chromic and phosphoric acids at 20, 40, 50 and $90 \mathrm{~V}$ respectively, with anodization duration of $12 \mathrm{~h}$ at $8{ }^{\circ} \mathrm{C}$. After the anodization formed oxide layer was chemically removed from the $\mathrm{Al}$ metal surface using etchant solution having $6 \mathrm{wt} \% \mathrm{H}_{3} \mathrm{PO}_{4}$ and $1.8 \mathrm{wt} \% \mathrm{H}_{2} \mathrm{CrO}_{4}$ at $60{ }^{\circ} \mathrm{C}$ for $2 \mathrm{~h}$ [33]. After removal, the sample was anodized again with same conditions for $12 \mathrm{~h}$. The determination of pore diameter, interpore distance, pore density, porosity and regularity ratio was performed by image analysis of SEM micrographs of PAAM using the Image-J 1.5 (NIH, USA) and WSxM 5.70 software (Nanotech, Spain) [34,35]. The morphological characterization was carried out using field emission scanning electron microscope (JEOL/JSM6380LA).

\section{Results and discussion}

\section{Pore formation mechanism}

Pore formation mechanism in PAAM was shown in the Fig. 1. It is generally accepted that, from the volume expansion stress model, porous layer is formed due to inward migration of $\mathrm{O}^{2-}, \mathrm{OH}^{-}$and outward migration of $\mathrm{Al}^{3+}$ ions [36]. After forming the oxide layer in PAAM, the volume of the aluminium being consumed is larger than the volume of the formed oxide layer. The lowest free energy resulted in the self-assembled, compact hexagonal arrays of pores. On the other hand, due to the spherical pore had the smallest surface area, PAAM has the most stable structure [37]. For the steady state growth of porous oxide layer, at the pore bases the incorporation of anions into the oxide layer occurs, gives a direct result of migration of electrolyte species. These migration of electrolyte species is related to

migration

of

$\mathrm{Al}^{3+}$ and $\mathrm{O}^{2-}, \mathrm{OH}^{-}$ions between oxide/ electrolyte and metal/oxide interfaces [38]. Migration of electrolyte species is differs in different types of electrolytes. In case of sulphuric (sulphates), oxalic (oxalates) and phosphoric (phosphates) acids it is related to migration rate of $\mathrm{O}^{2-}, \mathrm{OH}^{-}$ ions and in chromic acid (chromates) is related to migration rate of $\mathrm{Al}^{3+}$ ions [18]. May be this is the reason in case of chromic acid oxide layer is forming more than one layer compared with sulphuric, oxalic and phosphoric acids and it was also shown in the Fig. 1.

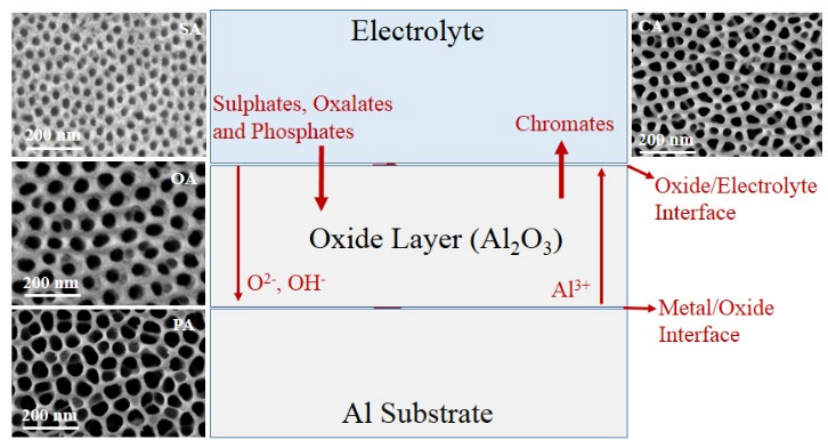

Fig. 1. Shows the growth mechanism of PAAM obtained in different electrolytes.

\section{Morphological aspects of PAAM}

In order to perform a detailed study of morphological aspects of PAAM, alumina membranes were prepared in $0.3 \mathrm{M}$ of sulphuric, oxalic, chromic and phosphoric acids with anodization potential of $20,40,50$ and $90 \mathrm{~V}$ respectively, about a temperature of $8^{\circ} \mathrm{C}$. SEM micrographs (Fig. 2 (a,b,c,d)), 2D Fast Fourier Transform (FFT) images (Fig. 2 (e,f,g,h)) and corresponding average profiles (Fig. 2 (i,j, $, \mathbf{k}, \mathbf{l}))$ of the FFT radius of PAAM were shown in the Fig. 2 in all four cases . From the Fig. 2, it was observed that PAAM were exhibited uniform array of pores in three
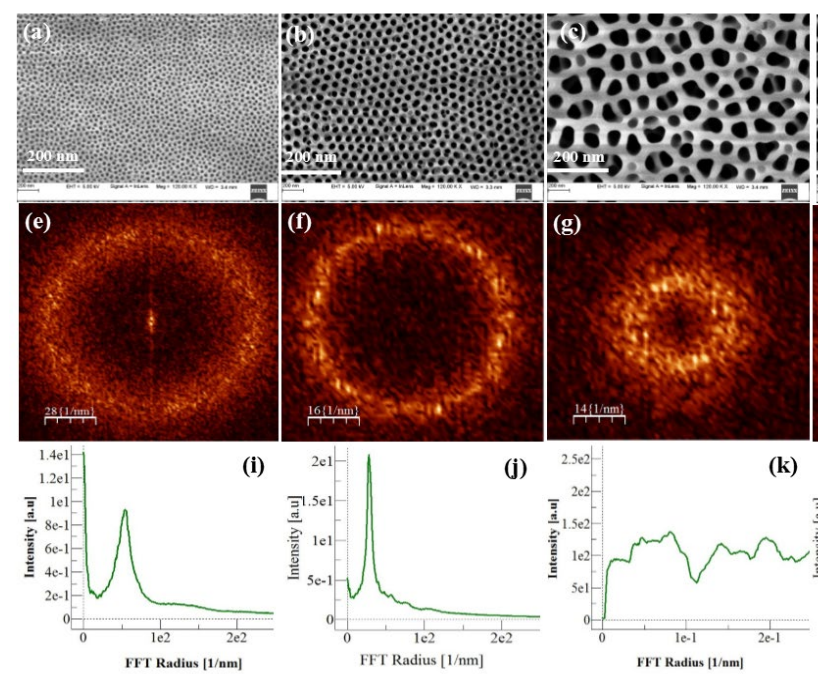

(k)

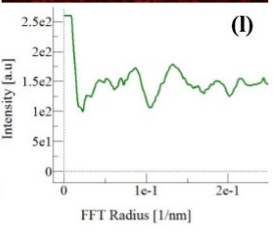

Fig. 2. SEM top views with 2DFFT and average profiles of the FFT radius of PAAM formed in $0.3 \mathrm{M}$ of sulphuric $(\mathbf{a}, \mathbf{e}, \mathbf{i})$, oxalic $(\mathbf{b}, \mathbf{f}, \mathbf{j})$, chromic $(\mathbf{c}, \mathbf{g}, \mathbf{k})$ and phosphoric $(\mathbf{d}, \mathbf{h}, \mathbf{l})$ respectively. 


\section{Advanced Materials Letters https://aml.iaamonline.org}

cases. But in case of oxalic acid highly ordered pores with hexagonal structure was observed. This is due to less number of anionic incorporation in oxalic acid compared with other acids [39]. This anionic content plays a major role in the steady-state growth of oxide layer during the anodization process. Image-J software was used to identify all nanopores in SEM image. Circularity, area and center of mass coordinates were measured for each pore in this step. The average pore diameter, interpore distance, porosity and pore density of PAAM were calculated using the formulae from the dedicated executable publication $[\mathbf{4 0 , 4 1 ]}$. Structural aspects such as pore diameter (Fig. 3(a)),

interpore distance (Fig. 3(b)), pore density (Fig. 3(c)) and porosity (Fig. 3(d)) versus four acids were shown in the Fig. 3. The average pore diameter and interpore distance in sulphuric, oxalic, chromic and phosphoric acids were observed as 32, 62, 128 and $226 \mathrm{~nm}$ and 62, 128, 254 and $450 \mathrm{~nm}$ respectively. It was noticed that highest porosity in case of sulphuric acid and pore density in case of oxalic acid. Fig. 4 illustrate the circularity (Fig. 4(a)) and regularity ratio (RR- Fig. 4(b)) of PAAM versus four acids. Pore shape was calculated using circularity coefficient [42] and in case of oxalic acid it was nearly equal to one compared with other acids. This is because of highly ordered hexagonal porous structure was formed in oxalic acid. This is due to highly ordered uniform porous structure is formed in oxalic acid case and it was confirmed from SEM image (Fig. 2). To obtain quantitative evolution of hexagonal arrangement of pores in PAAM, RR was estimated using WSxM software [43] and in oxalic acid case it is high value, compared with other acids. This is due to poor pore ordering in sulphuric and phosphoric acids compared with oxalic acid. It was confirmed by blurred ring on FFT profiles, intensity of radial average profile is also low in sulphuric and phosphoric acids. During the steady state growth rate of oxide formation in PAAM, oxide dissolution rate is more in oxalic acid compared with other acids. The structural aspects of PAAM data in four cases were noticed in Table 1.
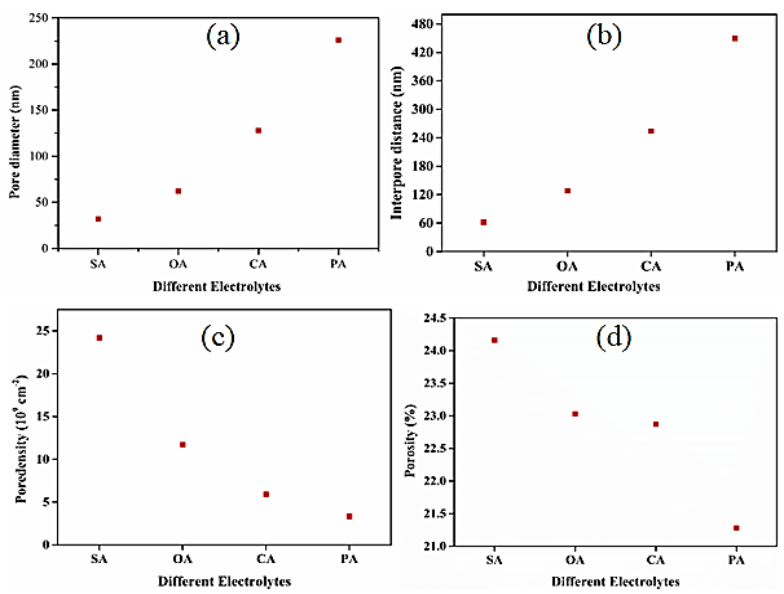

Fig. 3. Effect of pore diameter (Fig. 3a), interpore distance (Fig. 3b), pore density (Fig. 3c) and porosity (Fig. 3d) of PAAM on different electrolytes.
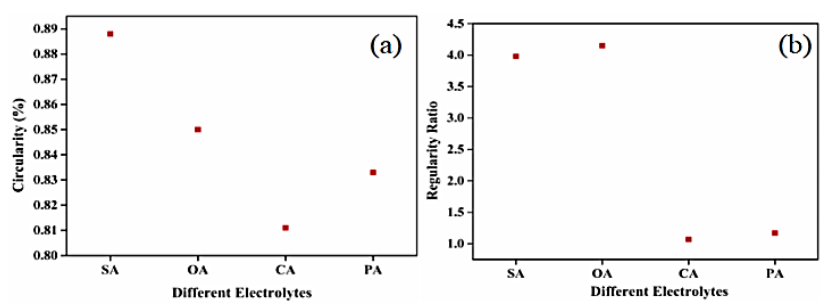

Fig. 4. Effect of circularity (Fig. 4a) and regularity ratio (Fig. 4b) as a function of different electrolytes.

Table. 1. Structural aspects of PAAM obtained in different electrolytes.

\begin{tabular}{|c|c|c|c|c|c|c|}
\hline $\begin{array}{l}\text { Electrolyte } \\
\text { Name }\end{array}$ & $\begin{array}{l}\text { Pore } \\
\text { Diameter } \\
(\mathrm{nm})\end{array}$ & $\begin{array}{l}\text { Interpore } \\
\text { distance } \\
(\mathrm{nm})\end{array}$ & $\begin{array}{l}\text { Pore } \\
\text { density } \\
\left(\mathrm{X} 10^{9} \mathrm{~cm}^{-2}\right)\end{array}$ & $\begin{array}{l}\text { Poro } \\
\text { sity } \\
(\%)\end{array}$ & $\begin{array}{l}\text { Regul } \\
\text { arity } \\
\text { ratio }\end{array}$ & $\begin{array}{l}\text { Circul } \\
\text { arity } \\
(\%)\end{array}$ \\
\hline Sulphuric acid & 32 & 62 & 24.19 & 24.16 & 3.98 & 0.888 \\
\hline Oxalic acid & 62 & 128 & 11.72 & 23.03 & 4.15 & 0.85 \\
\hline Chromic acid & 128 & 254 & 5.91 & 22.87 & 1.07 & 0.811 \\
\hline $\begin{array}{l}\text { Phosphoric } \\
\text { acid }\end{array}$ & 226 & 450 & 3.33 & 21.28 & 1.17 & 0.833 \\
\hline
\end{tabular}

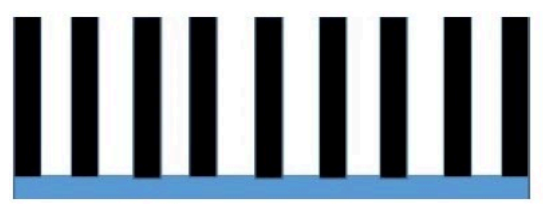

(a)

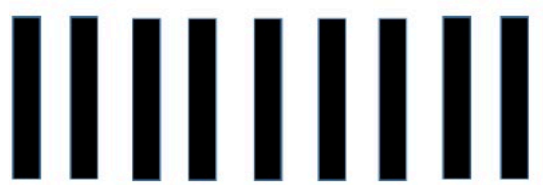

(b)

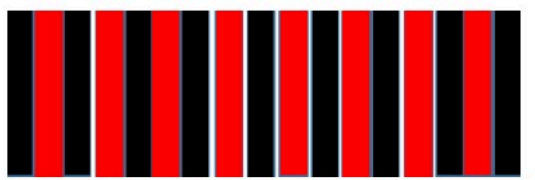

(c)

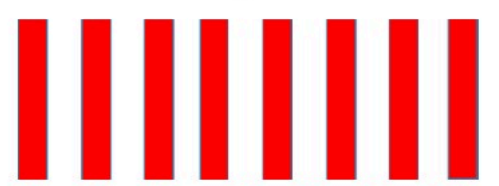

(d)

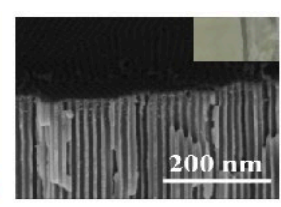

(e)

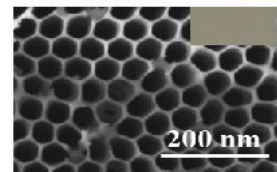

(I)

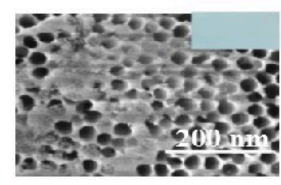

(g)

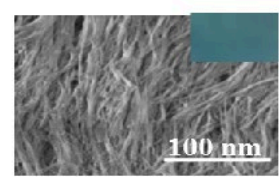

(h)
Fig. 5. Schematic of synthesis of $\mathrm{Cu}$ nanowires into the pores of PAAM (a) PAAM with highly ordered pores, (b) Free standing PAAM film, (c) Electroless deposition of copper nitrate solution into the pores of PAAM and (d) Formation of $\mathrm{Cu}$ nanowires. The corresponding FE-SEM images and variation of colour (inset) of the sample for each step (e, f, $\mathbf{g}$ and $\mathbf{h}$ ) of fabrication of $\mathrm{Cu}$ nanowires.

\section{Synthesis of Cu nanowire}

In-depth analysis of structural aspects of PAAM, it was noticed that highly ordered uniform array of pores were observed in $0.3 \mathrm{M}$ of oxalic acid at $40 \mathrm{~V}$. This PAAM is used to fabricate copper nanowire array via electroless deposition process which is shown in Fig. 5. After pore widening of PAAM for $30 \mathrm{~min}$ in $5 \mathrm{Wt} \% \mathrm{H}_{3} \mathrm{PO}_{4}$, it was found that the pore diameter was $\sim 68 \mathrm{~nm}$ with thickness $\sim 110 \mathrm{~mm}$. This is 
due to decrease in barrier layer thickness of PAAM with increasing the etching time [44]. Removal of barrier layer using saturated copper chloride solution is shown in the Fig. 5(b). Then $0.5 \mathrm{M}$ of copper nitrate solution was injected into the pores of free-standing PAAM and dried at room temperature (Fig. 5(c)) for $2 \mathrm{~h}$. Finally copper nanowires were obtained inside the pores of PAAM after annealing the sample at $60^{\circ} \mathrm{C}$ for $4 \mathrm{~h}($ Fig. 5(d)). During the annealing time, copper nitrate solution undergo thermal decomposition in the presence of excess of oxygen leading to the formation of copper nanowires. The conversion of the formed copper oxide into the pure copper nanowires after $4 \mathrm{~h}$ continuous annealing was confirmed from the colour change (Fig. 5(h)) of the sample and also from the EDX analysis. The corresponding FESEM images of PAAM and variation of colour of the sample (Inset) for each step was illustrated in Fig. 5(e) - Fig. 5(h) respectively. Fig. 6 shows the typical FE-SEM images of free standing $\mathrm{Cu}$ nanowires fabricated into the pores of PAAM by electroless deposition method [45]. $\mathrm{Cu}$ nanowires grown were highly homogeneous in shape, continuous and uniform throughout the surface of the membrane (Fig. 6(a)). Higher magnified $\mathrm{Cu}$ nanowire (Fig. 6(b)) array reveals that nanowires were randomly oriented on the pores of PAAM and tips of the nanowires aggregated into clumps. The cross-section image of PAAM is shown in Fig. 6(c). Inset images illustrate the variation of pore wall before and after deposition of $\mathrm{Cu}$ nanowires. It was observed that after deposition of $\mathrm{Cu}$ nanowires pore wall crushes near to the surface of PAAM. The EDX spectra showed in the Fig. 6(d) confirms the existence of $\mathrm{Cu}$. The dimensions of $\mathrm{Cu}$ nanowires are consistent with the average value of pore diameter of PAAM. It may be noted that such copper nanowires have wide ranging applications in gas sensing, field emission and photovoltaic devices, light emitting diodes and thin film solar cells [46].
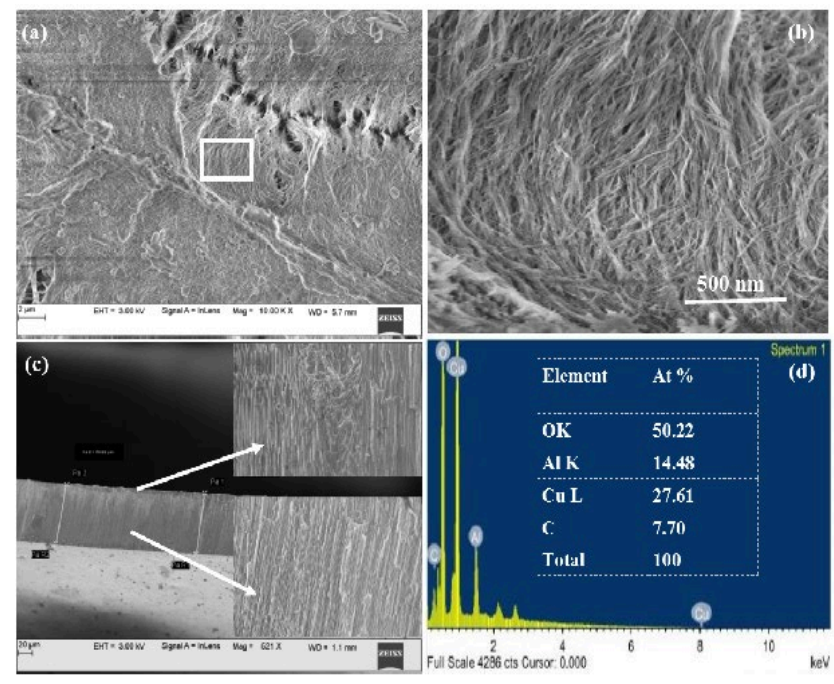

Fig. 6. (a) FE-SEM images of copper nanowires grown inside the pores of PAAM, (b) Higher magnified image of randomly oriented $\mathrm{Cu}$ nanowires, (c) Variation of cross-sectional image PAAM before and after growth of $\mathrm{Cu}$ nanowires and (d) EDX spectra of $\mathrm{Cu}$ nanowires.

\section{Conclusions}

In summary, PAAM were prepared in $0.3 \mathrm{M}$ of sulphuric, oxalic, chromic and phosphoric acid as electrolytes and with anodization potentials $(20,40,50$ and $90 \mathrm{~V})$ at a temperature of $8{ }^{\circ} \mathrm{C}$. Field-emission Scanning Electron Microscopy investigations confirm the pore formation in PAAM layers. Pore ordering was calculated using the Fast Fourier transform (FFT) of top view SEM micrographs. Pore arrangement analysis of PAAM was studied using Image-J and WSxM software. Morphological features of PAAM such as pore diameter, interpore distance, porosity and pore density were calculated in all electrolytes. Results show that, PAAM formed in oxalic acid having high regularity ratio and circularity compared with other cases. After pore widening duration of PAAM for $30 \mathrm{~min}$, pore diameter changes from $62 \mathrm{~nm}$ to $68 \mathrm{~nm}$. Copper nanowires were grown into the pores of PAAM by electroless deposition method. $\mathrm{Cu}$ nanowires were randomly oriented through the surface of the membrane and tips of the nanowires aggregate into clumps.

\section{Acknowledgment}

The one of the author P. Ramana Reddy wishes to acknowledge MHRD for their financial support throughout the research work.

\section{Author's contribution}

Author A: Designed and performed the experiments, analyzed data and cowrite the paper. Author B and C: Conceived of the study and acquisition data, participated in its design and coordination and helped to draft the manuscript. All authors have participated in (a) conception and design, or analysis and interpretation of the data; (b) drafting the article or revising it critically for important intellectual content; and (c) approval of the final version. All authors read and approved the final manuscript.

\section{Keywords}

Porous anodic alumina membranes, two-step anodization, circularity, pore diameter, porosity and pore density

Received: 25 May 2021

Revised: 16 July 2021

Accepted: 16 July 2021

\section{References}

1. Bai, A.; Hu, C.C.; Yang, Y.F.; Lin, C.C.; Electrochimica Acta, 2008, 53, 2258.

2. Reddy, P.R.; Ajith, K.M.; Udayashankar, N.K.; Journal of Materials Science: Materials in Electronics, 2016, 27, 5331.

3. Bruera, F.A.; Kramer, G.R.; Vera, M.L.; Ares, A.E.; Coatings, 2019 , 9, 115.

4. Stempniowski, W.J.; Bojar, Z.; Surface and Coatings Technology, 2011, 206, 265.

5. Zaraska, L.; Stempniowski, W.J.; Ciepiela, E.; Sulka, G.D.; Thin Solid Films, 2013, 534, 155.

6. Bruera, F.A.; Kramer, G.R.; Vera, M.L.; Ares, A.E.; Surfaces and Interfaces, 2020, 18, 100448.

7. Stempniowski, W.J.; Moneta, M.; Norek, M.; Michalska-Domanska, M.; Scarpellini, A.; Salerno, M.; Electrochimica Acta, 2016, 211, 453.

8. Reddy, P.R.; Ajith, K.M.; Udayashankar, N.K.; Ceramics International, 2016, 42, 17806.

9. Bruera, F.A.; Kramer, G.R.; Vera, M.L.; Ares, A.E.; Coatings, 2021, 11,309 . 
10. Cheng, C.; Electro-Chemo-Mechanics of Anodic Porous Alumina Nano-Honeycombs: Self-Ordered Growth and Actuation, Springer, 2015.

11. Jani, A.M.M.; Losic, D.; Voelcker, N.H.; Progress in Materials Science, 2013, 58, 636.

12. Santos, A.; Balderrama, V.S.; Alba, M.; Formentín, P.; FerréBorrull, J.; Pallarès, J.; Marsal, L.F.; Advanced Materials, 2012, 24, 1050.

13. Losic, D.; Simovic, S.; Expert Opinion on Drug Delivery, 2009, 6 , 1363.

14. St epniowski, W.J.; Salerno, M.; Manufacturing Nanostructures, 2014, 321.

15. Sulka, G.D.; Stempniowski, W.J.; Electrochimica Acta, 2009, 54, 3683.

16. Reddy, P.R.; Ajith, K.M.; Udayashankar, N.K.; Applied Physics A, 2018, 124, 765 .

17. Jessensky, O.; Müller, F.; Gösele, U.; Applied Physics Letters, 1998, $72,1173$.

18. Alkire, R.C.; Gogotsi, Y.; Simon, P.; Nanostructured Materials in Electrochemistry, John Wiley \& Sons, 2008.

19. Sulka, G.D.; Parkoไla, K.G.; Thin Solid Films, 2006, 515, 338.

20. Ramana Reddy, P.; Ajith, K.M.; Udayashankar, N.K.; Materials Science in Semiconductor Processing, 2020, 106, 104755.

21. Masuda, H.; Asoh, H.; Watanabe, M.; Nishio, K.; Nakao, M.; Tamamura, T.; Advanced Materials, 2001, 13, 189.

22. Lee, W.; Ji, R.; Ross, C.A.; Gösele, U.; Nielsch, K.; Small, 2006, 2, 978.

23. Montero Moreno, J.M.; Waleczek, M.; Martens, S.; Zierold, R.; Görlitz, D.; Martínez, V.V.; Prida, V.M.; Nielsch, K.; Advanced Functional Materials, 2014, 24, 1857.

24. Oshima, H.; Kikuchi, H.; Nakao, H.; Itoh, K.; Kamimura, T.; Morikawa, T.; Matsumoto, K.; Umada, T.; Tamura, H.; Nishio, K.; Applied Physics Letters, 2007, 91, 022508.

25. Reddy, P.R.; A.K.M.; Udayashankar, N.K.; Advanced Materials Letters, 2016, 7, 398.

26. Prida, V.M.; Vega, V.; García, J.; Iglesias, L.; Hernando, B.; Minguez-Bacho, I.; Magnetic Nano-and Microwires, Elsevier, 2015, pp.3-39.

27. Chi, C.S.; Lee, J.H.; Kim, I.; Oh, H.J.; Journal of Materials Science \& Technology, 2015, 31, 751.

28. Rashidi, F.; Masuda, T.; Asoh, H.; Ono, S.; Surface and Interface Analysis, 2013, 45, 1490.

29. Abd-Elnaiem, A.M.; Mebed, A.M.; Gaber, A.; Abdel-Rahim, M.A.; Journal of Alloys and Compounds, 2016, 659, 270.

30. Stempniowski, W.J.; Zasada, D.; Bojar, Z.; Surface and Coatings Technology, 2011, 206, 1416.

31. Reddy, P.R.; Ajith, K.M.; Udayashankar, N.K.; Materials Today: Proceedings, 2019, 19, 2633.

32. Bruera, F.A.; Kramer, G.R.; Vera, M.L.; Ares, A.E.; Superlattices and Microstructures, 2019, 130, 103.

33. Stempniowski, W.J.; Moneta, M.; Norek, M.; Michalska-Domanska, M.; Scarpellini, A.; Salerno, M.; Electrochimica Acta, 2016, 211, 453.

34. Vega, V.; García, J.; Montero-Moreno, J.M.; Hernando, B.; Bachmann, J.; Prida, V.M.; Nielsch, K.; ACS Applied Materials \& Interfaces, 2015, 7, 28682.

35. Stempniowski, W.J.; Doma. ń. ska M.; Norek, M.; Czujko, T.; Materials Letters, 2014, 117, 69.

36. Shimizu, B.K.; Kobayashi, K.; Thompson, G.E.; Wood, G.C.; Philosophical Magazine B, 1991, 64, 345.

37. Yang, Z.B.; Hu, J.C.; Li, K.Q.; Zhang, S.Y.; Fan, Q.H.; Liu, S.A.; in IOP Conference Series: Materials Science and Engineering IOP Publishing, 2017, p. 012003.

38. Searson, P.C.; Moffat, T.P.; Critical Reviews in Surface Chemistry, 1994, 3,171

39. Thompson, G. E.; Wood, G. C.; in Treatise on Materials Science and Technology, Edited by J. C. Scully (Elsevier, 1983), pp. 205-329.

40. Stempniowski, W.J.; Nowak-St cpniowska, A.; Bojar, Z.; Materials Characterization, 2013, 78, 79 .
41. Ciepiela, E.; Zaraska, L.; Sulka, G.D.; GridSpace2/Collage Executable Paper Http://Collage. Cyfronet. Pl/Hillebrand-Grains 2011.

42. Zaraska, L.; Stempniowski, W.J.; Sulka, G.D.; Ciepiela, E.; Jaskuła, M.; Appl. Phys. A, 2014, 114, 571.

43. Stempniowski, W. J.; Choi, J.; Yoo, H.; Doma. ń. ska M.; Chilimoniuk, P.; Czujko, T.; Materials Letters, 2016, 164, 176.

44. Suchitra, S.M.; Reddy, P.R.; Udayashankar, N. K.; Materials Today: Proceedings, 2016, 3, 2042.

45. Ren, X.; Huang, X.; Zhang, H.; He, M.; Frontiers of Materials Science in China, 2007, 1, 312.

46. Rathmell, A.R.; Bergin, S. M.; Hua, Y.L.; Li, Z.Y.; Wiley, B.J.; Advanced Materials, 2010, 22, 3558. 